Article

\title{
Invisible Locative Media: Key Considerations at the Nexus of Place and Digital Journalism
}

\author{
Ivar John Erdal ${ }^{1, *}$, Kjetil Vaage $\varnothing \mathrm{ie}^{1}{ }^{1}$, Brett Oppegaard ${ }^{2}$ and Oscar Westlund ${ }^{1,3,4}$ \\ ${ }^{1}$ Faculty of Media and Journalism, Volda University College, 6103 Volda, Norway; E-Mails: erdali@hivolda.no (I.J.E.), \\ kvo@hivolda.no (K.V. Ø.) \\ 2 School of Communications, University of Hawai'i at Manoa, Honolulu, HI 2550, USA; E-Mail: brett.oppegaard@hawaii.edu \\ ${ }^{3}$ Department of Journalism and Media Studies, Oslo Metropolitan University, 0130 Oslo, Norway; \\ E-Mail: oscar.westlund@oslomet.no \\ ${ }^{4}$ Department of Journalism, Media and Communication, University of Gothenburg, 40530 Gothenburg, Sweden \\ * Corresponding author
}

Submitted: 1 October 2018 | Accepted: 21 December 2018 | Published: 19 February 2019

\begin{abstract}
Mobility and location-awareness are pervasive and foundational elements of contemporary communication systems, and a descriptive term to synthesize them, "locative media", has gained widespread use throughout mobile media and communication research. That label of "locative media", though, usually gets defined ad hoc and used in many different ways to express a variety of related ideas. Locative features of digital media increasingly have changed from visible location-driven aspects of user interfaces, such as check-in features and location badges, toward more inconspicuous ways of relating to location through automated backend processes. In turn, locative features-whether in journalism or other formats and content types-are now increasingly algorithmic and hidden "under the hood", so to speak. Part of the problem with existing classifications or typologies in this field is that they do not take into account this practical shift and the rapid development of locative media in many new directions, intertwining ubiquitous digital integration with heterogeneous content distinctions and divergences. Existing definitions and typologies tend to be based on dated practices of use and initial versions of applications that have changed significantly since inception. To illustrate, this article identifies three emerging areas within digital journalism and mobile media practice that call for further research into the locative dimensions of journalism: the situational turn in news consumption research, platform-specific vis-a-vis platform-agnostic mobile news production, and personalised news.
\end{abstract}

\section{Keywords}

digital journalism; locative media; mobile journalism; mobile media; mobile news; mobile technology; place-based media

\section{Issue}

This article is part of the issue "Emerging Technologies in Journalism and Media: International Perspectives on Their Nature and Impact," edited by John Pavlik (Rutgers University, USA).

(C) 2019 by the authors; licensee Cogitatio (Lisbon, Portugal). This article is licensed under a Creative Commons Attribution 4.0 International License (CC BY).

\section{Introduction}

Mobile devices have become an integral part of everyday life for most citizens in the world (e.g., Newman, Fletcher, Kalogeropoulos, Levy, \& Nielsen, 2018). Oftentimes mobile devices are introduced to people in their youth, and they quickly establish frequent patterns of use, and de- velop so-called mobile media lives (Westlund \& Bjur, 2013; cf. Deuze, 2012). People use their mobile devices, portable and ubiquitous by nature, for media consumption and media production in all sorts of places and contexts. Consequently, media organisations (and the journalists that work for them) are embracing emerging mobile technologies-including the place-oriented locative 
aspects of them-in a myriad of quickly evolving ways. For example, the production of news today is closely linked to journalists using smartphones to reach sources during newsgathering and to create new multimedia work on the move. Mobile journalists (MoJos), as an extreme illustration of this technological shift, rely entirely on their mobile devices for the production and publishing of news, local to international in scope. Distribution of news for mobile devices moreover has become a point of emphasis in the industry and has become entangled with editorial content management systems, including through the development of key mobile-oriented assessment metrics (Westlund \& Quinn, 2018). Moreover, an overwhelming majority of all of the news accessed, shared and commented (e.g., Costera Meijer \& Kormelink, 2015) on social media platforms, and social media use in general, takes place with mobile devices in numerous places.

In recent years a handful prolific journalism studies scholars have offered broad and important approaches to the nexus of place and journalism (see, e.g., Gutsche \& Hess, 2019; Peters, 2012; Schmitz Weiss, 2014; Usher, in press). All of these advance our understanding of the multidimensional concept of "place". This is our ambition also with this article, albeit in a narrower way, focusing on location-based information in digital journalism. This marks an area that has been explored, tested, and integrated during the past decade, creating exciting new affordances in the pursuit of public engagement. Locative media is one of the ways such locationbased features can be conceptualized. Goggin, Martin and Dwyer (2015, p. 43) identify locative media as involving modern mobile media's "capacity to gather and represent information about the location of a device and its users", something that enables, for example, the visualisation of the user's actions or the tailoring of news to a present position. Studies of locative media and locative journalism have for several years addressed various related aspects, such as digital design (Ladly, 2008; Messeter, 2009; Nyre, Bjørnestad, Tessem, \& Øie, 2012), content production (Fagerjord, 2011, 2017; Løvlie, 2011; $\varnothing \mathrm{ie}, 2013$; Oppegaard \& Grigar, 2014) and use (Farrelly, 2017; Humphreys, 2007; Saker \& Evans, 2016; Saker \& Frith, 2018) of locative media. Yet these studies only take narrow glances at the fundamental changes in digital journalism related to locative media.

While a growing body of research has been focusing more precisely on locative media and locative journalism, as noted above, it has not been fully incorporated, as we argue it should, in the more general body of research into diverse aspects at the core of digital journalism, from use-case scenarios to user-centered filtering mechanisms. We support the sentiment of Westlund and Quinn (2018), who write:

Our overall suggestion for the future research agenda is to treat mobile as a key element of digital journalism. Scholars must start taking mobile media seriously. The future of digital journalism is mobile, and thus dig- ital journalism scholarship would benefit from analyzing this ongoing shift.

In neighbouring efforts, much research into digital journalism has been successful in distinguishing "online" from legacy media, while typically failing to investigate the role of mobile devices for production and consumption of news (cf. review in Westlund \& Quinn, 2018). Similarly, there is a large body of research into the intersection of digital journalism and social media, and this research often has been built on problematic assumptions (see critical review in Lewis \& Molyneux, 2018), to which we can add that it also largely overlooks how the study of patterns and attitudes, etc., on Twitter, Facebook, or Instagram are inexorably connected to the material use of mobile devices (and much less so to desktop and laptop computers). While taking the ubiquitous nature of social media for granted, researchers typically fail to see the importance of contemporary mobile devices in facilitating and shaping various forms of communication, entertainment, and information, including participatory and citizen journalism (Westlund \& Ekström, 2018). There are indeed empirical studies into the sensemaking of mobile media in news media organizations-i.e., what they think and do with mobile technology and devices-from both its formative years (Westlund, 2011, 2012) and the present (Chua \& Westlund, 2019, in this issue). Such research offers a glimpse into the changing nature of how news media approach emerging technologies, such as locative media enabled by mobile devices.

Ultimately, mobile technologies of all sorts-as the interface through which many people experience the world (Farman, 2012)-must be brought more to the forefront via research into the intersection of digital journalism, social media, and other emerging technologies, to truly understand what's happening and also to address in this context more fully what is "hidden under the hood" with regards to how data gathering and analysis happen behind the scenes in relation to positioning and various end-user services and revenue streams.

To illuminate this construct, this article argues that location features in digital journalism are increasingly hard to identify and therefore represent a research design challenge for contemporary and future scholarly inquiry. That does not mean location and locative features are less important, unimportant, or should now be disregarded. These features just are becoming more subtly incorporated and more critical to the ubiquitous veiling of mobile-app influence, increasing the value of studying them but making such study more difficult. Without a more precise definition of locative media, this line of inquiry gets even messier. This complication is particularly complex in journalism, since location and place already provide well-established values to news and constitute core elements of journalistic production, distribution, and consumption.

Along these lines, this article will review current work within mobile media and locative media before 
discussing previous attempts of developing typologies and classifications of locative media. Its objective is to survey the field and create foundations for further systematic approaches to analyzing the content of mainstream legacy media in terms of locativeness. In addition, as examples of impact, this article identifies three key areas within digital journalism that call for a further exploration of locative dimensions: 1) the situational turn in news consumption research, 2) platformspecific vis-a-vis platform-agnostic mobile news production, and 3) personalised news. For the first concept, the situational turn in news consumption research refers to how researchers from across nearby subfields-from journalism studies to mobile media and communication studies-have devoted increasing attention to situational conditions (spaces and places) in relation to news consumption. Second, with platform-specific vis-avis platform-agnostic mobile news production, we refer to journalistic content created uniquely by and for mobile devices, as different from various related forms of repurposing of similar content from other mediums. Third, personalised news points to the tailoring of news exposure for individuals, based on explicit choices or on preferences set through generally covert uses of algorithms.

\section{Locative Media Has Been a Moving Target for Researchers}

Frith and Saker (2017) find that while the popularity of early and explicitly locative applications might have faded, the importance and integration of place and position-triggered content through locative media has not. It has rather been domesticated across various other types of mobile media, including social media, and also diffused across numerous scholarly disciplines, engaged by many but owned by no one. Location-technology use, in turn, has become more difficult to identify and measure as it melds into common features across platforms and search engines. So instead of space and place being simplified, reduced, and delineated by modern digital forms, they are made more complex and veiled in practice (Couldry \& McCarthy, 2004, p. 7). As Schudson (1978) states, technology is a commonly used explanation for developments in journalism. However, this is more of an abstract theoretical reflection than a working theory, making it difficult to operationalize and investigate (pp. 31-35).

Geographical proximity or "place" is and has been a fundamental news value of journalism for centuries, as the foundational "where" element of local, regional, and national news. A recent book-length focus on this value is found in Gutsche and Hess (2019, p. 3), who explore the intersection between journalism and geography, addressing issues such as how journalism affects perceptions of location, the connections to digital and physical spaces where it is being practiced, and how all of this relates to the power and legitimacy of journalism. Also focusing on place, Usher (in press) offers a three-part framework relating to digital news maps in which journalists can be 1) map-makers, 2) map-users, and 3) map-subjects. All three relate to the journalists' authority in publishing representations of places. About a decade ago, coinciding with the release of the Apple iPhone, location technologies were approached by newsrooms as opportunities that could be appropriated and made salient via mobile news services (Westlund, 2011, 2012), and thus journalism experiments involving location were highly visible, easy to identify, and relatively prevalent. News media has so far dabbled in this fascination with new digital technologies and new ways of making and using news, related to place, though, without significantly altering business models in pursuit of those opportunities ( $\varnothing \mathrm{ie}, 2015)$. Location functionalities have simultaneously developed from visible locationdriven user interfaces-such as check-in features and location badges-towards more "invisible" or inconspicuous ways of relating to location. Reese (2016) argues that recent scholarship on spatial aspects has shown how concepts such as networks, spheres, and fields have become even more relevant when one needs to think of digital news production less in terms of formal legacy news media organizations and more in terms of the many assemblages across diverse spaces that may be involved.

Locative features are now increasingly incorporated in algorithms in various ways and increasingly "hidden under the hood". Evans and Saker (2017) argue in a similar vein that while the use of Foursquare has declined, the key features of this application are now found in all major social networks. They $(2017$, p. 69) use the term "zombie media" to describe, for example, Foursquare "haunting" media development and shaping new technologies. One of these major recent developments in the collection and creation of location data is that it ordinarily now happens across multiple services and through large map platforms such as Google Maps, Mapbox, and Carto. Together with the so-called ambient location data gathered from your phone's Global Positioning System (GPS), Wi-Fi, Bluetooth, General Mobile Radio Service (GMRS) signals, Near-Field Communication (NFC), and any nearby proximity beacons, this expanding network infrastructure has gradually improved location accuracy and usefulness, which allows apps to register where you are, where you have been, and how long you have been there, even if you don't use the check-in button. The app provider can then identify meaningful locations and incorporate this context into your personal profile and into other built-in app features, such as recommendations, various nearby notifications, ads, matching services, etc. These under-researched developments need to be approached from the perspectives of media strategies, newsroom practices, and journalistic content, as will be described further.

As Schudson (1978) argued decades ago, and Lewis and Westlund (2016) picked up again a few years ago, emerging technologies have led to changes in many as- 
pects of journalistic practice, but they do not delve into the specifics of distinctively mobile content. The role of place in locative journalism is aligned with Schudson's (1978) technology argument but not fully absorbed. Place, like technology, is a fundamental part of journalism. However, it may be difficult to identify the "place" component in any particular journalistic artifact in order to conduct rich analyses of those (not that we suggest place should be entirely separated from other contextual aspects). Buchanan (2009) argued that place has been such a fundamental part of journalism, and at the same time so multi-layered and ubiquitous, that focusing on the news relationship to place and space has been too complicated in a traditional story- and content-dominated practice. With the deep-data capabilities of mobile technologies, and the tracking and precision those afford, locative journalism could create a revival of scholarly interest in place, especially as associated with technological impacts on journalism. But, first, we have to figure out exactly what we are dealing with here.

Scholars have to date approached categorizations or typologies of locative media in many ways, in an effort to create common ground in a new field of research. We found in the literature a wide range of concepts describing locativity (and locative apps) and classifying them as such. Some of these approaches have focused upon user activity (Nitins \& Collis, 2013), application affordances (Oppegaard, 2015), activities enabled by mobile interfaces (Farman, 2012, 2014), and the applications' primary focus as it pertains to geolocative functions (Farrelly, 2017), as proposed bases for such types of classification.

So far, though, such approaches only have skimmed the surface of investigating how levels of contextsensitivity or locativeness are experienced, particularly in the context of journalism studies. What we have found, is a tendency for existing definitions and typologies to be based on older practices of use, and earlier versions of applications that have by now changed significantly. These applications also will continue to develop rapidly, along with machine learning, Artificial Intelligence, position prediction, the increase in personalized news, etc. As a primary model for what routinely happens in this realm, one of the most heavily studied apps in locative scholarly literature has been Foursquare (Frith, 2013; Hjorth \& Richardson, 2016; Lindqvist et al., 2011; Saker \& Frith, 2018). Aiming for a moving target, scholars have been chasing Foursquare's iterations as they have undergone significant changes in design, technical frameworks, and even in basic content characteristics for years. Foursquare abandoned prominent location featuressuch as location sharing, check-ins, etc., in 2014, with the launch of Foursquare 8.0-but still has retained a sense of locativeness through other means and through robust backend systems. So how do scholars aim at this kind of dynamic and rapidly morphing target without missing wildly?

\section{Mobile Media and Communication Research}

One of the first challenges to overcome is to be clear about how the terms mobile media, mobile technology, and locative media are defined in previous research. As the term "cell phone" may be rendered obsolete by related rapid technological development, Campbell (2013) argued that mobile communication technology could best be defined as "devices and services that support mediated social connectivity while the user is in physical motion" (Campbell, 2013, p. 9). Mobile communication technology is not necessarily used on the move, he wrote, but it can "afford, i.e., make possible, mobility during mediated communication", Campbell (2013, p. 10) calls this "the affordance of mobility". Likewise, Westlund (2010, p. 92) argued that the term "mobile device" is more suitable than mobile "phone", as the mobile technology has developed into an apparatus that integrates multimedia functions and many different technologies, including software, hardware, semiotic systems, etc., into a powerful and highly portable computing device.

Oppegaard (2015, p. 210) leans on Campbell (2013) when describing that mobile devices do not need to be used while on the move but that the possibility for "mobility during mediated communication" is perhaps the central affordance at play. He also points to Turkle (2008) in describing one of the fundamental properties of mobile technology as its being part of a social identity, personal, and "always on, always on you" (Turkle, 2008, p. 121), which allows users to think of their mobile device as "an extension of the self," personalizing and customizing it (Campbell, 2008, 2013, p. 11).

Wilken (2012, p. 243) defines locative media as "media of communication that are functionally bound to a location". Wilken and Goggin (2015, p. 2) acknowledge that while location-based media can be said to involve the use of information about a location, the locative aspect is somewhat difficult to define, and argue that locative media have gone well beyond mobile social software, social networking applications, and so-called check-in applications. Importantly, with Facebook successfully incorporating such functionality into their platform, locative actions have been embedded into everyday life in the most-used social media platform in the world. Moreover, Oppegaard (2015, p. 202) argues that mobility and location awareness have become common, underlying characteristics of contemporary, wireless communication systems. For Sutko and de Souza e Silva (2011), mobile interfaces now function as "technological filters" that help "users manage interactions with city space (Saker \& Frith, 2018).

Frith (2015) discusses de Souza e Silva's (2006) concept of "hybrid space," and the ways in which these hybrid spaces are formed, through a combination of three elements: social interaction, digital information, and physical space. He further argues that digital information plays a role in shaping how people "read physical places", as digital location information is "providing new ways of seeing, experiencing, and understanding the 
city" (Frith, 2015, p. 8). In short, something different begins happening to "individuals and societies when virtually everything is located or locatable" (Gordon \& de Souza e Silva, 2011, p. 2). At the beginning of this transition, researchers generally focused on investigating ways in which mobile devices disconnected users from their surrounding spaces, with distracted users documented as unaware of events happening within close proximity (de Souza e Silva \& Sutko, 2008). But the quick establishment and domestication of mobile technologies in the past decade has changed this dynamic dramatically, leading scholars back into spatiality and social connections based on proximity (Campbell, in press). Studying Mobile Virtual Reality (MVR), Saker \& Frith (2018, p. 12) argue that this technology may promise a move away from "hybrid spaces" toward a "third stage" of mobile media research that they identify as "dislocated space", again stressing the argument that research in a rapidly changing field, such as Mobile Communication Studies, involves working with, establishing, and developing the analytical vocabulary.

The effects of proximity - to put it simply, that things are more closely related the nearer they are together physically-are so profound and fundamental that they have been described as Tobler's (1970) First Law of Geography. With the development of mobile technologies, that line of thought also has been extended into an economic model of public space described as the Second Law of Geography, in which things that know where they are can act on their locational knowledge, allowing spatially enabled things to have increased financial and functional utility (Foresman \& Luscombe, 2017). Despite the successes of some commercial locative projects, such as Pokémon GO, journalism does not have a business model for locative journalism yet. Some of the most creative appropriations of hybrid space, by mobile-media artists, for example, could be considered journalistic in nature and could provide inspiration for locative journalism (de Souza e Silva, Duarte, \& Damasceno, 2017; Zeffiro, 2012). Some journalism projects also have been created as academic experiments, most without profits and large audiences in mind, creating clear findings of interest in place-based media (Kramp, 2018; Nyre et al., 2012; Øie, 2012, 2013, 2015; Oppegaard \& Rabby, 2016). But, despite such potential, journalism organizations primarily have been content with easy and straightforward connections to legacy bread-and-butter products, such as localized traffic and weather reports (Schmitz Weiss, $2013,2014)$. The struggle to establish spatial journalism with distinguished content has created a conundrum in the industry, in which digital and mobile media has yet to make many meaningful connections to place (Schmitz Weiss, 2018). We think part of this stunted growth relates to a lack of precision in shared terminology and nascent development of theoretical frameworks.

This sampling demonstrates that the literature on locative media covers a wide variety of conceptual approaches to-and uses of-mobile devices through mo- bile apps, from mapping services (such as Google Maps) to social applications (such as Instagram) that affords users opportunities to both make and consume locative media (Farman 2014; Frith 2015; Goggin \& Wilken, 2015; de Souza e Silva \& Sheller, 2015; Sutko \& de Souza e Silva, 2011). Among all of these apps with locative features, common ground can be found in the idea that location data plays (and will play) an increasingly important part in the development of different kinds of hybrid spaces, or digital-information environments illuminating place through mobile technologies.

\section{Existing Typologies and Classifications of Locative Media}

There are several ways to approach typologies of locative media, too. The literature contains a wide range of different concepts describing locativity and attempts to classify it in a comprehensible and operationalized manner. Some of these approaches have user activity (Nitins \& Collis, 2013), application affordances (Oppegaard, 2015), interfaces (Farman, 2012), and geolocative functionality (Farrelly, 2017) as a base for their classification. This includes interactivity based on location, maps, usergenerated content, technical built-in algorithms such as geo-fences and personal interests and behaviour, and content tailored to suit the user's movement on a mi$\mathrm{cro} / \mathrm{meso}$ level.

Drawing upon de Souza e Silva and Delacruz (2006) and Stenton et al. (2007), Oppegaard and Rabby (2016, p. 625) argue that location-embedded media content can trigger mobile devices and "deliver the right experience at the right moment", combining the users' mobility with location-aware interfaces to situate knowledge "in actual and relevant contexts", as a form of (AR) until now mostly explored in location-based games (Goggin et al., 2015, p. 58), everyday urban navigation (Liao \& Humphreys, 2015), art and literature projects (Loevlie, 2009, 2011), and museums (Oppegaard \& Rabby, 2016, p. 623).

Nitins and Collis (2013) remind us that not only rapid development in technologies have led to diverse academic disciplinary approaches to locative media, which also have led to uncertainty about how we define and analyze it, but the complex situated nature of mobile media complicates our understandings as well. Thus, a taxonometrical uncertainty is prevalent in the field of locative media. This includes scholarly debates on what locative media artifacts are and what they should be. Nitins and Collis (2013) therefore seek a common language to allow locative media scholars and users to better communicate with each other. Based on the use and purpose of the analyzed application, they suggest that locative media can be divided into five main categories: social annotative, commercial annotative, navigational, location-based services, and location-based gaming, although these categories also have many clear overlaps.

Oppegaard (2015, p. 203) argued that the landscape of mobile content has evolved into a "heterogeneous 
and fragmented ecosystem", continually stretching definitional boundaries, and with little overarching control by large industry actors. He further claimed that while a lot of early mobile media content could be described as different forms of "shovelware" or "repackaged material dumped on mobile screens" (p. 204), new forms of "mobile-born" and customized content keeps emerging at an increasing rate. Oppegaard (2015, p. 204) also argued that researchers have not been able to keep up with the rapid pace of innovation, and identified one of the knowledge-gaps to be filled as typology, or the ability "to clearly describe mobile app artifacts". The author then aims to close this gap by describing locative apps as a genre (p. 205).

A similarity between the two classification systems suggested in these previous paragraphs is the foundation built on what the apps allow the users to do and how, classifying potential courses of action. Oppegaard defined this as an affordances approach. As such, it could fall under Peters' (2012, p. 699) criticism about too much focus on the potential ways users could engage with journalism. One of Oppegaard's $(2015$, p. 207) claims is that, at the time of writing, the relative novelty of mobile devices, combined with mobile spatial experiences being an emerging field, makes for an ideal time to attempt a classification. What neither Nitin and Collis (2013) or Oppegaard (2015) do, though, is to formulate a more clear-cut typology of mobile media content. This leaves us wanting for theoretical and analytical vocabulary when studying legacy media's ventures into locative media and aiming to classify contemporary journalistic practices and, especially, when considering variations in content. We consider improvement of the precision of terms an important part of future boundary work in locative media.

\section{Invisible, Omnipresent Locative Features}

Next, we turn our focus to three key developments within digital journalism that urgently call for further exploration of locative dimensions, as illustrations of this type of boundary work: 1) the situational turn in news consumption research, 2) platform-specific visa-vis platform-agnostic mobile news production, and 3) personalised news. These three areas of interest have emerged as pivotal points to the authors in their ongoing processes of reviewing the research frontier, and following developments in the telecom and media industries. These are not isolated dimensions but rather interconnected developments that contribute to making the field more complex. They are part of a change in which locative features are becoming an increasingly ubiquitous part of digital journalism.

\subsection{The Situational Turn in News Consumption Research}

The way we organize our daily schedule and activities are affected by developments in mobile-media use. Credit cards, wireless and mobile conversations across continents, and mobile messages (Ling \& Pedersen, 2006; Tjora, 2011) are some examples of these changes. These phenomena have inspired a growing body of research on how mobile communication technologies change the ways in which we communicate with each other, and interact with spaces and places (Goggin \& Wilken, 2012; Ling, 2004). News consumption with mobile devices was-in its formative years-envisioned to take place "on the go" when other news media were not readily available. A special section on mobile news consumption published in 2015 reviewed and advanced research into the intersection of mobile news and place, alongside patterns, place and participation (Westlund, 2015). As evidenced by several related studies, such as the annual Digital News Reports from the Reuters Institute for the Study of Journalism (RISJ), people are nowadays turning to their mobile devices for news both on the go and whilst at home and at work (Newman et al., 2018).

While news consumption can occur in numerous spaces, there is also research embracing the notion that news content is intrinsically related to a certain situation, a given context, and a specific place, and that this is also the case for news consumption. As Peters $(2012$, p. 697) formulates it: "News consumption is not just something we do, it is something we do in a particular place". Studies like these can be described as a situational turn in the research on media users.

Specific location-tailored elements in news production, distribution, and content play a significant role in this sort of mobile journalism consumption. Media use takes place in a broader range of situations than generally described in earlier audience studies. Bjur et al. (2014) have examined media use in what they call socio-spatial contexts, finding that how people relate to media content is highly affected by their surroundings. One of their conclusions is that in some cases, the interpretation of media content varies more between different contexts than between different media platforms (Bjur et al., 2014, p. 24). A given media platform, for example, may have a set of situational affordances making it more suitable for some journalistic genres than others (Schrøder \& Steeg Larsen, 2010). Locative media, or locative features, has become one way of adapting to the context of the user, as one element of a situational turn in news consumption.

One of Goggin et al.'s (2015) conclusions is that the bulk of development and innovation can be found not in news journalism but in other adjacent communication genres, such as advertising, public relations, and entertainment (Goggin et al., 2015, p. 48). Schmitz Weiss (2013, p. 436) discusses some of the potential uses of mobile media, in line with Peters (2012, p. 699). Her conclusion is that legacy media generally do not offer geolocated or locative content of significance. She is supported by Oppegaard and Rabby (2016), claiming that media companies have chosen not to utilize the many apparent technological affordances available for mobile devices (p. 622), instead mainly grabbing the lowest- 
hanging fruit, such as utilizing the potential for more precisely localized traffic and weather reports.

Schröder (2014) has studied how audiences relate to different media platforms in different situations and why. He found that our physical and technical surroundings play a significant role in our repertoire of news in a given context, coining the term "fluctuating audiences" to describe the phenomenon. Findings like these are presumably one of the foundations for Peters' $(2015$, p. 2) call for research on how audiences relate to (news) media, "as new technologies allow users to blur familiar boundaries and co-create new communicative spaces" as "the ubiquity and personal proximity of recent digitalization increasingly means experiencing multiple places simultaneously and continuously and it is unclear how this impacts our perception and experience of information and the world in general".

Moreover, it is worth noting that some news publishers have adapted their production and publishing of mobile news to contemporary patterns of news consumption by producing videos intended for audiences watching them in silent mode with their smartphones, such as at the Times of India, including logos, subtitles and other visuals (Westlund \& Quinn, 2018).

While ad-hoc projects-even at the highest levels of journalism-are promising and encouraging signs for the industry, we argue that a more fundamental mobile-oriented (and significantly place-oriented) paradigm shift really is needed for journalistic content to avoid being subsumed in the noise of all of the other information sources more vigorously and aggressively pursuing the opportunities of mobile affordances. Unlike the ways in which newspapers and radio adjusted to the competition of television journalism, each maintaining a niche, and then all three of those had to adapt together to the Internet, mobile devices can absorb all media forms that have come before it, creating something similar but often better. A smartphone can deliver all of those types of news (text-focused, ear-focused, eyefocused) yet in more dynamic ways and precisely tailored to place, aligned with the physical environment.

\subsection{Platform-Specific Vis-a-Vis Platform-Agnostic Mobile News Production}

Pavlik $(2001,2004)$ had early ideas about proposing a research agenda for the study of journalism and technological change, identifying four areas of technological influence on journalism: 1) how journalists work, 2) journalistic content, 3) newsroom structures, and 4) the relationships between news organisations, journalists and publics. In the content realm, Pavlik (in press) argued that technology could make journalism content more immersive and engaging through both technological advancements, such as 360-degree video, and aesthetic strategies, such as through more nonlinear narratives. Research into immersive journalism since has begun to gain a foothold in digital journalism studies (e.g., Baía
Reis \& Coelho, 2018). The scholarly discourse surrounding mobile media has clear similarities to that of convergence journalism in the mid-2000s. Some definitions of "convergence" had a built-in, explicit or implicit ideal, where all media organizations aimed for more convergence, utilizing the technological potentials (e.g., Dailey, Demo, \& Spillman, 2005; Quinn, 2005). Comparing this to locative media, we argue that while there is a technological development and opportunity here, a simple framing of "news providers have not taken advantage of the potential of locative media" follows a similar vein of assuming that it is rational and reasonable-with current resources, technologies, industry cultures, practitioner skill sets, etc. - to appropriate locative media into widespread journalistic practice at this point. But it might not be the right time yet, either, when considered in more depth and amid the complexities of such a major shift in resources, focus, and revenue sources. There may be various undocumented, misunderstood, or generally underappreciated reasons for media organizations to not devote major resources in this direction at this moment, often lumped together as "not a part of the current business model", or these organisations also may use locative features in ways that are not being detected or appreciated by researchers, hidden both to users "under the hood" and to researchers, "under the radar". While these questions have been discussed thoroughly in relation to convergence, they need to be addressed in future research on locative media and journalism. Ultimately, contemporary news publishers can and also do employ either platform-specific or platform-agnostic approaches to mobile (and other platforms) in their news production (e.g., Westlund \& Quinn, 2018). Customization of platform specific content has been a common rhetoric and strategy, and has also been brought along with publishing for non-proprietary platforms and the overall dislocation of journalism that this has resulted in. However, when faced with a multitude of platforms, proprietary and non-proprietary by nature, the news publishers may also find reason to produce platform-agnostic news that can travel to a plethora of platforms, such as native mobile news applications, social media feeds, as well as voice-assisted speakers reading out the news aloud (Ekström \& Westlund, in press).

Oppegaard and Rabby (2016) created a prototype of a service-journalism app as a way of exploring the possibilities of place-based journalism. With a focus on user engagement, which they share with Peters (2012, p. 698), as a design principle, the authors argued that the mobile news app-created and tested in the context of a local festival-should engage the user on different levels (Oppegaard \& Rabby, 2016, p. 626). The approach was similar to that of Nyre et al. (2012) and $\varnothing$ ie (2012), who also created and tested their LocaNews reader on real users in the context of a festival. The findings also are similar: Oppegaard and Rabby (2016, p. 631) found that proximity significantly affected user involvement and satisfaction. 


\section{A conclusion of LocaNews is that:}

Although it may be easy to design a medium that affords location-dependent journalism, it is very difficult to reorient the established journalistic procedures and textual conventions so that they effectively exploit the possibilities of the new medium. (Nyre et al., 2012, p. 312)

If we consider locative media as part of the general technological development of journalism, there are clear parallels to the literature on newsroom convergence, which is considered mainly as technology-driven but at the same time embedded in a particular setting of journalistic cultures and practices (Avilés \& Carvajal, 2008; Erdal, 2009 , 2011). Several studies of the implementation of technologies in newsrooms have concluded that professional cultures are usually not particularly open to change and innovation but "remarkably resilient and resistant to change" (Ryfe, 2009, p. 198). A similar discussion is found in Jones (2017), exploring use of 360-degree immersive films in journalism in the UK, and a recent cross-cultural comparison of innovation (and social media strategies) in the US and Scandinavia has found there to be a generally slow adaptation of new technologies but also differences between countries and companies (Lehtisaari et al., 2018). Importantly, researchers still have to address in more detailed ways what "slow" and "open" refer to, especially if no benchmarks are being used.

In research review on mobile news, Westlund (2013, p. 19) concluded that legacy news media are not prioritizing unique journalistic content for mobile devices. He said:

Instead they are increasingly leaning on utilising machines for automated repurposing of journalistic content, while at the same time making use of technological functionalities to provide an experience with the news customised for the (perceived) affordances of the mobile device.

Others have explained this low-level investment as caused by shrinking revenues in the media industry, which have left little capacity to fund research, development, and innovation regarding the potential of mobile media technology (Goggin et al., 2015, p. 55). While this technological shift was initially something that only larger media companies could afford to try, the industry strategy appears aimed at lowering costs as well as integrating more easy-to-use solutions, such as adopting robust third-party systems, rather than participating directly in ambitious research-and-development initiatives, even if their business futures-and the future of sovereign democracies-depend on it. This could mean a reciprocal craving for experimentation with mobile content and thus a potential for a grass-roots increase in this kind of journalism in the immediate future, requiring thought leaders in the industry, though, to push and support more locative-media projects while also shifting the larger news-organization paradigm to support those exploratory initiatives.

\subsection{Personalised News}

Mobile sites and applications creating personalised news piqued the interests of many news media organizations and personnel with the rise of touchscreen smartphones around 2007-2008, and precursors to contemporary forms of personalization were inscribed into some of the mobile news services built around that time (e.g., Westlund, 2012). Personalisation of the news is sometimes made explicit by means of communicating to users that they can make news preferences displayed with priority, and sometimes those features are entirely hidden under the hood, simply having algorithms personalising the news exposure for individuals based on their choices within the program (sometimes even producing news for individuals or small groups in a distinct geographical space, such as a street or block). Mobile news applications that currently do not personalize news, rather than those that do, are the exception.

Recent studies of incidental news consumption show that users get news in situations and places that they were not expecting to get news (Boczkowski, Mitchelstein, \& Matassi, 2018). This phenomenon is closely linked to the dimension of situational news. In this case, though, social media plays a dominant role, and algorithms, including location data, facilitate how the media would appear for the individual user in order to provide a personalised and place-based touch. Boczkowski et al. (2018) finds that the pervasive use of mobile devices for various everyday communication, their technological affordances, and their temporalspatial features affect the "anytime and anywhere" of news consumption. One consequence of this shifting power structure is that news organisations lose control when it comes to filtering which information, when, and where to address the users.

One of the forms this filtering may take is (AR). Pavlik and Bridges (2013) discuss AR and claim that this format can be seen as:

A natural extension of what place-based journalism has historically done best-stories are put in a local context and act as a supplement to a citizen's direct experience with the world. An artifact of this style is evident in the first part of any story in a newspaperthe dateline that identifies the location where a story was reported. (Pavlik \& Bridges, 2013, p. 21)

News selection via algorithms also is part of this environment.

In relation to the increasing personalization by social media and news organisations, and the debate on boundaries between algorithmic and editorial selections, Thurman, Moeller, Helberger and Trilling (2018, p. 29) an- 
alyzed data from 26 countries and found that audiences overall believe that algorithmic selection of news that is guided by a user's past consumption behaviour is a better way to get news than through traditional editorial curation (when editors decide what you get, in what order, and displayed with what type of prominence). They also found those who access news from a mobile device to:

Have higher levels of agreement that any sort of news selection is a good thing. However, this effect is stronger for automated personalization based on a user's own behaviour than for editorial selection or automated peer-based personalization. (Thurman et al., 2018)

Although this may not initially be great news for media organizations, Thurman et al. (2018, p. 29) conclude that their findings point toward possibilities for personalization for young people and mobile users in particular. If audiences want something, like personalised news, that legacy media organisations are not giving them, audiences will migrate to meet their needs and desires, leaving behind the less-adaptable. In the case of personalised news, most media organizations have made some commitment to fostering that type of independent curatorial choice. That said, developing algorithmic news preferences for audiences seems only an elementary step in the evolution of mobile news, particularly when considering the vast potential of place-based news and locative media in general. Therefore, personalising news may be a start today but more complex and nuanced associations among people, place, and information are destined for tomorrow, raising an imperative for news organisations to adapt now or risk obsolescence later. These provided examples, in turn, could present the foundations for a systematic approach to analyzing the content of legacy media in terms of locativeness.

\section{Conclusion}

Locative features of digital media increasingly have changed from visible location-driven user interfaces, such as check-in features and location badges, to more inconspicuous ways of relating to location. Locative features, whether in journalism or other formats and content types, are now more and more incorporated in the algorithms in various ways and increasingly hidden "under the hood". That does not mean they are shrinking in importance or deserve less scholarly attention. As prominent and structurally important examples, three recent developments within digital journalism have been identified that call for a further exploration of the locative dimensions of journalism. These are interconnected developments that are part of a change where locative features are becoming an increasingly ubiquitous and essential part of digital journalism.

As this article has shown through a discussion of existing definitions and attempts to categorize locative media, it is clearly more manageable to investigate and analyze the visible features of a given application, system, or format. Part of the problem with existing classifications or typologies, though, is that they don't take the rapid development of locative media into account, don't proactively embrace emerging mobile technologies and practices, such as the mobile media shared via auto apps or produced by drones, and don't bring to the foreground the otherwise invisible aspects of locative media. There is a clear tendency for existing definitions and typologies to be based on older practices of use, and earlier versions of applications that have by now changed significantly. Previous features that characterised the locativeness of an application may have been redesigned, removed, or have changed user practices and may be found in other features within the application instead.

In extension of this article we make a call for further conceptualization and modelling of locative media in the salient case of digital journalism. While remaining focused on what is otherwise invisible and hidden under the hood, future works could draw upon recent and more general conceptualizations, such as "smartphones as metamedia" by Humphreys, Karnowski and von Pape (2018) in the field of mobile media and communication, as well as previously discussed research into space and place in journalism by scholars such as Gutsche, Hess, Schmitz Weiss and Usher, respectively. In terms of public good, we believe that locativity has much potential in-and therefore needs to be studied in relation tothe content and personal addressability of digital journalism. Important questions for a working model include how content will be produced and tailored, what kind of content is addressed, and also if and how such content is considered locative?

\section{Conflict of Interests}

The authors declare no conflict of interests.

\section{References}

Avilés, J. A. G., \& Carvajal, M. (2008). Integrated and cross-media newsroom convergence: Two models of multimedia news production-The cases of Novotecnica and La Verdad Multimedia in Spain. Convergence, 14(2), 221-239.

Baía Reis, A., \& Coelho, A. (2018). Virtual reality and journalism. Digital Journalism, 6(8), 1090-1100.

Bjur, J., Schrøder, K. C., Hasebrink, U., Courtois, C., Adoni, H., \& Nossek, H. (2014) Cross-media use-unfolding complexities in contemporary audiencehood. In N. Carpentier, K. C. Schrøder, \& L. Hallett (Eds.), Audience transformations: Shifting audience positions in late modernity (pp. 15-29). New York, NY: Routledge.

Boczkowski, P. J., Mitchelstein, E., \& Matassi, M. (2018). "News comes across when I'm in a moment of leisure": Understanding the practices of incidental news consumption on social media. New Media \& So- 
ciety. https://doi.org/10.1177/1461444817750396

Buchanan, C. (2009). Sense of place in the daily newspaper. The Journal of Media Geography, 4, 62-84.

Campbell, S. W. (2008). Mobile technology and the body: Apparatgeist, fashion, \& function. In J. Katz (Ed.), Handbook of mobile communication studies (pp. 153-164). Cambridge, MA: MIT Press.

Campbell, S. W. (2013). Mobile media and communication: A new field, or just a new journal? Mobile Media \& Communication, 1(1), 8-13.

Campbell, S. W. (in press). From frontier to field: Old and new theoretical directions in mobile communication studies. Communication Theory.

Chua, S., \& Westlund, O. (2019), Audience-centric engagement, collaboration culture and platform counterbalancing: A longitudinal study of ongoing sensemaking of emerging technologies. Media and Communication, $7(1), X X-X X$.

Costera Meijer, I., \& Kormelink, T. G. (2015). Checking, sharing, clicking and linking. Digital Journalism, 3(5), 664-679.

Couldry, N., \& McCarthy, A. (2004). MediaSpace: Place, scale and culture in a media age (comedia). London: Routledge.

Dailey, L., Demo, L., \& Spillman, M. (2005). The convergence continuum: A model for studying collaboration between media newsrooms. Atlantic Journal of Communication, 13(3), 150-168.

Deuze, M. (2012). Media life. Boston, MA: Polity Press.

De Souza e Silva, A. (2006) From cyber to hybrid: Mobile technologies as interfaces of hybrid spaces. Space and Culture, 3, 261-278.

De Souza e Silva, A., \& Sutko, D. M. (2008). Playing life and living play: How hybrid reality games reframe space, play, and the ordinary. Critical Studies in Media Communication, 25(5), 447-465.

De Souza e Silva, A., \& Sheller, M. (Eds.). (2015). Mobility and locative media. Mobile communication in hybrid spaces. New York, NY: Routledge.

De Souza e Silva, A., Duarte, F., \& Damasceno, C. S. (2017). Creative appropriations in hybrid spaces: Mobile interfaces in art and games in Brazil. International Journal of Communication, 11, 1705-1728.

Ekström, M., \& Westlund, O. (in press). The dislocation of news journalism: A conceptual framework for the study of epistemologies of digital journalism. Media and Communication, 7(1).

Erdal, I. J. (2009). Cross-media (re) production cultures. Convergence, 15(2), 215-231.

Erdal, I. J. (2011) Coming to terms with convergence journalism: Cross-media as a theoretical and analytical concept. Convergence, 17(2), 213-223.

Evans, L., \& Saker, M. (2017). Location-based social media: Space, time and identity. Cham: Springer.

Fagerjord, A. (2011). Between place and interface: Designing situated sound for the iPhone. Computers and Composition, 28(3), 255-263.

Fagerjord, A. (2017). Toward a rhetoric of the place:
Creating locative experiences. I. L. Potts \& M. J. Salvo (Eds.), Rhetoric and experience architecture (pp. 225-240). West Lafayette: Parlor Press.

Farman, J. (2012). Mobile interface theory: Embodied space and locative media. New York, NY: Routledge.

Farman, J. (Ed.). (2014). The mobile story. Narrative practices with locative technologies. New York, NY: Routledge.

Farrelly, G. E. (2017). Claiming places: An exploration of people's use of locative media and the relationship to sense of place (Unpublished doctoral dissertation). University of Toronto, Toronto.

Foresman, T., \& Luscombe, R. (2017). The second law of geography for a spatially enabled economy. International Journal of Digital Earth. doi:10.1080/ 17538947.2016 .1275830

Frith, J. (2015). Smartphones as locative media. Cambridge: Polity Press.

Frith, J., \& Saker, M. (2017). Understanding Yik Yak: Location-based sociability and the communication of place. First Monday, 22(10).

Goggin, G., \& Wilken, R. (2012). Mobile technology and place. London: Taylor \& Francis.

Goggin, G., Martin, F. \&, Dwyer, T. (2015). Locative news. Mobile media, place informatics, and digital news. Journalism Studies, 16(1), 41-59.

Gordon, E., \& de Souza e Silva, A. (2011). Net locality: Why location matters in a networked world. West Sussex: Wiley-Blackwell.

Gutsche, R. E., Jr., \& Hess, K. (2019). Geographies of journalism: The imaginative power of place in making digital news. New York and London: Routledge.

Humphreys, L. (2007). Mobile social networks and social practice: A case study of dodgeball. Journal of Computer-Mediated Communication, 13(1), 341-360. doi:10.1111/j.1083-6101.2007.00399.x

Humphreys, L., Karnowski, V., \& von Pape, T. (2018). Smartphones as metamedia: A framework for identifying the niches structuring smartphone use. International Journal of Communication, 12, 2793-2809.

Jones, S. (2017). Disrupting the narrative: Immersive journalism in virtual reality. Journal of Media Practice, 18(2/3), 171-185.

Kramp, L. (2018). Journalism in a deeply mediatized city. A locative approach to urban reporting. In L. Peja, N. Carpentier, F. Colombo, M. F. Murru, S. Tosoni, R. Kilborn, ... P. Pruulmann-Vengerfeldt, Current perspectives on communication and media research ( $\mathrm{pp}$. 177-201). Bremen: Edition Lumiere.

Ladly, M. (2008). Designing for mobile: A walk in the park. Canadian Journal of Communication, 33(3), 525-536.

Lehtisaari, K., Villi M., Grönlund, M., Lindén, C.-G., Mierzejewska, B., Picard, R., \& Roepnack, A. (2018). Comparing innovation and social media strategies in Scandinavian and US Newspapers. Digital Journalism, 6(8), 1029-1040.

Lewis, S., \& Molyneux, L. (2018). A decade of research on social media and journalism: Assumptions, blind 
spots, and a way forward. Media and Communication, 6(4), 11-23.

Lewis, S. C., \& Westlund, O. (2016). Mapping the humanmachine divide in journalism. In T. Witschge, C. Anderson, D. Domingo, \& A. Hermida (Eds.), Handbook of digital journalism. New York, NY: SAGE.

Liao, T., \& Humphreys, L. (2015). Layar-ed places: Using mobile augmented reality to tactically reengage, reproduce, and reappropriate public space. New Media \& Society, 17(9), 1418-1435.

Lindqvist, J., Cranshaw, J., Wiese, J., Hong, J., \& Zimmerman, J. (2011, May). I'm the mayor of my house: Examining why people use foursquare-a social-driven location sharing application. In Proceedings of the SIGCHI conference on human factors in computing systems (pp. 2409-2418). ACM.

Ling, R. (2004). The mobile connection: The cell phone's impact on society. San Francisco, CA: Morgan Kaufman.

Ling, R., \& Pedersen, P. E. (Eds.). (2006). Mobile communications: Re-negotiation of the social sphere. London: Springer Science \& Business Media.

Loevlie, A. S. (2009). Textopia: Designing a locative literary reader. Journal of Location Based Services, 3(4), 249-276.

Loevlie, A. S. (2011). Locative literature: Experiences with the textopia system. International Journal of Arts and Technology, 4(3), 234-248.

Messeter, J. (2009). Place-specific computing: A placecentric perspective for digital designs. International Journal of Design, 3(1), 29-41.

Newman, N., Fletcher, R., Kalogeropoulos, A., Levy, D. A., \& Nielsen, R. K. (2018). Reuters Institute digital news report 2018. Retrieved from http://media. digitalnewsreport.org/wp-content/uploads/2018/06/ digital-news-report-2018.pdf?x89475

Nitins, T., \& Collins, C. (2013) 'Grounding the Internet': Categorising the geographies of locative media. Media International Australia, 146(1), 69-78. doi:10.1177/1329878X1314600110

Nyre, L., Bjørnestad, S., Tessem, B., \& Øie, K. V. (2012). Locative journalism: Designing a location-dependent news medium for smartphones. Convergence, 18(3), 297-314.

Oppegaard, B., \& Rabby, M. K. (2016). Proximity: Revealing new mobile meanings of a traditional news concept. Digital Journalism, 4(5), 621-638.

$\varnothing \mathrm{ie}$, K. V. (2012). Sensing the news: User experiences when reading locative news. Future Internet, 4(1), 161-178.

$\varnothing \mathrm{ie}, \mathrm{K}$. V. (2013). Location sensitivity in locative journalism: An empirical study of experiences while producing locative journalism. Continuum, 27(4), 558-571.

$\varnothing \mathrm{ie}$, K. V. (2015). News narratives in locative journalismRethinking news for the mobile phone. Journal of Media Practice, 16(3), 245-262.

Oppegaard, B. (2015). Mobility matters: Classifying locative mobile apps through an affordances approach. In
J. M. Aguado, C. Feijóo, \& I. J. Martínez (Eds.), Emerging perspectives on the mobile content evolution ( $\mathrm{pp}$. 203-222). Hershey, PA: IGI-Global Press.

Oppegaard, B., \& Grigar, D. (2014). The interrelationships of mobile storytelling: Merging the physical and the digital at a national historic site. In J. Farman (Ed.), The mobile story: Narrative practices with locative technologies (pp. 17-33). New York, NY: Routledge.

Oppegaard, B., \& Rabby, M. K. (2016). Proximity: Revealing new mobile meanings of a traditional news concept. Digital Journalism, 4(5), 621-638.

Pavlik, J. V. (2001). Journalism and new media. New York, NY: Columbia University Press.

Pavlik, J. V. (2004). A sea-change in journalism: Convergence, journalists, their audiences and sources. Convergence, 10(4), 21-29.

Pavlik, J. V. (in press). Journalism in the age of virtual reality: How experiential media are transforming news. New York, NY: Columbia University Press.

Pavlik, J. V., \& Bridges, F. (2013). The emergence of augmented reality (AR) as a storytelling medium in journalism. Journalism \& Communication Monographs, 15(1), 4-59.

Peters, C. (2012). Journalism to go: The changing spaces of news consumption. Journalism Studies, 13(5/6), 695-705.

Peters, C. (2015). Introduction. Journalism Studies, 16(1), 1-11. doi:10.1080/1461670X.2014.889944

Quinn, S. (2005). Convergence's fundamental question. Journalism studies, 6(1), 29-38.

Reese. S. D. (2016). The new geography of journalism research. Digital Journalism, 4(7), 816-826.

Ryfe, D. M. (2009). Broader and deeper: A study of newsroom culture in a time of change. Journalism, 10(2), 197-216.

Saker, M., \& Evans, L. (2016). Everyday life and locative play: An exploration of Foursquare and playful engagements with space and place. Media, Culture \& Society, 38(8), 1169-1183.

Saker, M., \& Frith, J. (2018). Locative media and sociability: Using location-based social networks to coordinate everyday life. Architecture_MPS, 14(1), 1-21. doi:10.14324/111.444.amps.2018v14i1.001

Saker, M., \& Frith, J. (2018). From hybrid space to dislocated space: Mobile virtual reality and a third stage of mobile media theory. New Media \& Society. doi:10.1177/1461444818792407

Schmitz Weiss, A. (2013). Exploring news apps and location-based services on the smartphone. Journalism and Mass Communication Quarterly, 90(3), 435-456.

Schmitz Weiss, A. (2014). Place-based knowledge in the twenty-first century: The creation of spatial journalism. Digital Journalism, 3(1), 116-131.

Schmitz Weiss, A. (2018). Journalism conundrum: Perceiving location and geographic space norms and values. Westminster Papers in Communication and Culture, 13(2), 46-60. 
Schrøder, K. C. (2014). News media old and new. Journalism Studies, 16(1), 60-78. doi.10.1080/1461670X. 2014.890332

Schrøder, K. C., \& Steeg Larsen, B. (2010). The shifting cross-media news landscape. Journalism Studies, 11(4), 524-534. doi:10.1080/14616701003638392

Schudson, M. (1978). Discovering the news: A social history of American newspapers. New York, NY: Basic Books.

Stenton, S. P., Hull, R., Goddi, P. M., Reid, J. E., Clayton, B. J., Melamed, T. J., \& Wee, S. (2007). Mediascapes: Context-aware multimedia experiences. IEEE MultiMedia, 14(3).

Sutko, D. M., \& de Souza e Silva, A. (2011). Locationaware mobile media and urban sociability. New Media \& Society, 13(5), 807-823. doi:10.1177/ 1461444810385202

Thurman, N., Moeller, J., Helberger, N., \& Trilling, D. (2018). My friends, editors, algorithms, and I: Examining audience attitudes to news selection. Digital Journalism. doi:10.1080/21670811.2018.1493936.

Tjora, A. H. (2011). Invisible whispers: Accounts of SMS communication in shared physical space. Convergence, 17(2), 193-211.

Tobler, W. (1970). A computer movie simulating urban growth in the Detroit region. Economic Geography, $46,234-240$.

Turkle, S. (2008). Always-on/always-on-you: The tethered self. Handbook of mobile communication studies, 121.

Usher, N. (in press). News cartography and epistemic authority in the era of big data: Journalists as map makers, map users, and map subjects. New Media \& Society.

Westlund, O. (2010). New(s) functions for the mobile:
A cross-cultural study. New Media \& Society, 12(1), 91-108.

Westlund, O. (2011). Cross-media news work-Sensemaking of the mobile media (r)evolution. Gothenburg: JMG. Retrieved from https://gupea.ub.gu.se/ bitstream/2077/28118/1/gupea_2077_28118_1.pdf

Westlund, O. (2012). Producer-centric versus participation-centric: On the shaping of mobile media. Northern Lights, 10(1), 107-121.

Westlund, O. (2013) Mobile news. A review and model of journalism in an age of mobile media. Digital Journalism, 1(1), 6-26.

Westlund, O. (2015). News consumption in an age of mobile media: Patterns, people, place, and participation. Mobile Media \& Communication, 3(2), 151-159.

Westlund, O., \& Bjur, J. (2013). Mobile news life of young. In K. Chumskey \& L. Hjorth (Eds.), Mobile media practices, presence and politics. The challenge of being seamlessly mobile (pp. 180-197). New York, NY: Routledge.

Westlund, O., \& Ekström, M. (2018). News and participation through and beyond proprietary platforms in an age of social media. Media and Communication, 6(4), $1-10$.

Westlund, O., \& Quinn, S. (2018). Mobile journalism and MoJos. In Oxford research encyclopaedia of communication. Oxford: Oxford University Press. doi:10.1093/acrefore/9780190228613.013.841.

Wilken, R. (2012) Locative media: From specialized preoccupation to mainstream fascination. Convergence, 18(3), 243-247.

Wilken, R., \& Goggin, G. (Eds.). (2015). Locative media. New York, NY: Routledge.

Zeffiro, A. (2012). A location of one's own: A genealogy of locative media. Convergence, 18(3), 249-266.

\section{About the Authors}

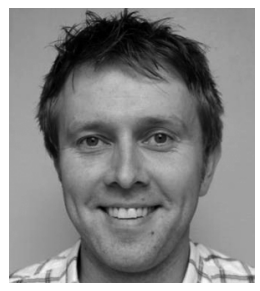

Ivar John Erdal (PhD) is an Associate Professor at the Faculty of Media and Journalism at Volda University College, and a visiting scholar at the Department of Media and Communication at the University of Sydney. His research interest lies mainly in digital journalism and mobile media. Other research areas include cross-media production, organisation studies and journalism education. Erdal is a partner in the research project Organizing for Media Innovation, funded by the Norwegian Research Council.

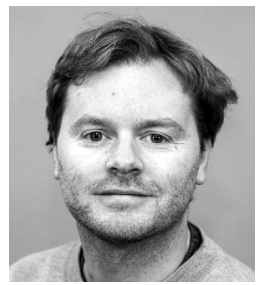

Kjetil Vaage $\emptyset$ ie is an Assistant Professor at the Faculty of Media and Journalism at Volda University College. Øie has authored and co-authored several articles on locative media and locative journalism both from the perspective of design, content and use. Other research areas and pedagogical projects include new media, mobile media, representations of realities and communication -and media design. 

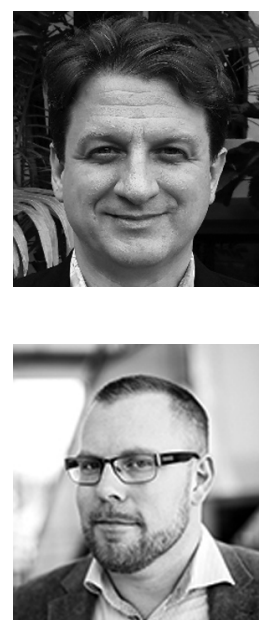

Brett Oppegaard (PhD) is an Associate Professor at the University of Hawai'i. He studies medium distinctions within ubiquitous computing environments, primarily focused upon the impacts of mobile technologies. His research has been supported by U.S. federal agencies, such as the National Endowment for the Humanities and the National Park Service, but also by private foundations and corporations, such as Vision Maker Media and Google.

Oscar Westlund (PhD) is a Professor at the Department of Journalism and Media Studies at Oslo Metropolitan University, where he leads the OsloMet Digital Journalism Research Group and the OsloMet Digital Journalism Research Fellowship program and Focus Seminar series. He holds secondary appointments at Volda University College and at the University of Gothenburg. Westlund specializes in journalism, media management and news media consumption for proprietary news media platforms such as news sites and mobile applications, as well as with regard to social media platforms non-proprietary to the news media. Westlund is the Editor-in-Chief of Digital Journalism, and has also guest edited special issues for a handful other leading international journals. He currently leads a research project called The Epistemologies of Digital News Production, funded by the Swedish Foundation for Humanities and Social Sciences. 